\title{
FORMULATION AND EVALUATION OF RED PALM OLEIN NANOEMULSION
}

\author{
FEBIA SARI ${ }^{1 *}$, KASMIRUL RAMLAN SINAGA ${ }^{1}$, DONALD SIAHAAN ${ }^{2}$
}

${ }^{1}$ Department of Pharmaceutical Technology, Faculty of Pharmacy, Universitas Sumatera Utara, Medan, Indonesia. ${ }^{2}$ Indonesian Oil Palm Research Institute, Medan, Indonesia. Email: feby490@gmail.com

Received: 09 April 2018, Revised and Accepted: 25 May 2018

ABSTRACT

Objective: The objective of this study is to formulate and evaluate the red palm olein (RPO) nanoemulsion using spontaneous emulsification method.

Methods: Nanoemulsion formulated by spontaneous emulsification method using the comparison of surfactant (tween 80) and cosurfactant (sorbitol) concentration with the variation of RPO concentration. Evaluation of the stability of the nanoemulsion preparation includes centrifugation test, viscosity, $\mathrm{pH}$, organoleptic observation (odor, color, clarity, and phase separation), and particle size measurement during 12 weeks storage at room temperature.

Result: The results showed that all nanoemulsion preparations were transparent yellow, characteristic odor, type weights $1.0166-1.0641$ g/ml, and stable for 12 weeks storage at room temperature. The smallest particle size was produced by the nanoemulsion preparation in a formula of the concentration of $5 \%$, which was $67,64 \mathrm{~nm}$.

Conclusion: RPO can be formulated as a nanoemulsion by spontaneous emulsification method. RPO with a $5 \%$ concentration is very stable for 12 weeks storage.

Keywords: Red palm olein, Nanoemulsion, Spontaneous emulsification, Surfactant, Cosurfactant.

(C) 2018 The Authors. Published by Innovare Academic Sciences Pvt Ltd. This is an open access article under the CC BY license (http://creativecommons. org/licenses/by/4. 0/) DOI: http://dx.doi.org/10.22159/ajpcr.2018.v11i9.26532

\section{INTRODUCTION}

Palm oil is a vegetable oil that has many types of minor components such as carotenoids, which have the potential as a source of natural provitamin A and can replace the source of synthetic Vitamin A which is relatively expensive. Carotenoid compounds contained in palm oil are an important compound for the body that acts as an antioxidant. Antioxidant compounds are widely found in vegetables, fresh fruits, and spices because they contain Vitamin C, Vitamin E, carotene, lycopene and flavonoids that can prevent a free chain reaction of free radicals. The antioxidant compounds contained in the oil can be used to prevent damage caused by degradation. Antioxidant compounds in the body serve as an antidote to free radicals, so the body is protected from various degenerative diseases and slow the aging process (aging). Compared with synthetic antioxidants, natural antioxidants are safer, easily absorbed by the body, have more rapid biological functions, and more effective in preventing cancer [1].

Red palm oil contains $\beta$-carotene 375 ppm, Vitamin E 559-1000 ppm in the form of tocopherol $18-22 \%$ and tocotrienol $78-82 \%$. Carotenoids contained in red palm oil consisted of $\beta$-carotene $54.4 \%, \alpha$-carotene $36.2 \%$, $\gamma$-carotene $3.3 \%$, lycopene $3.8 \%$, and xantofil $2.2 \%$. To improve the stability and solubility in water, carotenoids can be dissolved in the oil phase in an oil-in-water emulsion $(\mathrm{o} / \mathrm{w})$ so that it can be easily formulated. Nanotechnology provides an opportunity to increase the solubility of an active component and increase its bioavailability. In the field of pharmaceuticals, the manufacture of nanometer-scale particles shows increased solubility in water and biological availability (bioavailability) [2].

Nanoemulsion is a transparent, translucent emulsion system and is a water-in-oil dispersion stabilized by a film coating of a surfactant or surfactant molecule having a droplet size of 50-500 $\mathrm{nm}$ [3]. Nanoemulsion has a transparent or translucent physical form. Nanoemulsion has several advantages such as having a larger surface area and free of energy. Nanoemulsion shows no problem in instability as in macroemulsion, i.e., creaming, flocculation, koalesens and sedimentation. Nanoemulsions can also be formed with various formulations such as cream, fluid gel, spray, and foam. In addition, the nanoemulsion is also not toxic, and not irritating; therefore, it can be applied easily through the skin or mucous membranes [4]. Nanoemulsions can also increase absorption and bioavailability of drugs, help to stabilize the hydriphobic active substances, and have the efficiency on rapid penetration of some drugs [5]. Nanoemulsion is one of the interesting vehicles, which is mostly developed to enhance in vitro and in vivo absorption and bioavailability of drug through the skin [6-10].

\section{MATERIALS AND METHODS}

\section{Materials}

Red palm olein (RPO) was received as gift sample from Indonesian Oil Palm Research Institute (Medan, Indonesia), tween 80, sorbitol, methylparaben, propylparaben, and Aquadest. All other chemicals were of analytical grade

\section{Formulation of nanoemulsion}

Formulation of nanoemulsion was using spontaneous emulsification method. RPO is added to the oil phase which has added methylparaben and propylparaben to homogeneous add a Smix solution which is a mixture of surfactant and cosurfactant, then stirred with the magnetic stirrer until homogeneous. Aquadest is added by means of titration, stirred continuously until nanoemulsion is formed which is marked by the formation of a translucent solution. The percentage of the ingredients of nanoemulsion formula (Table 1) was modified from the nanoemulsion formula which was carried out in the previous study by Asmarani and Wahyuningsih [11].

\section{Physicochemical evaluation of RPO nanoemulsion} Organoleptic test

Observations on any changes of color, odor, clarity, and phase separation were made. 
pH measurement

$\mathrm{pH}$ values were measured at $25^{\circ} \mathrm{C}$ using a digital $\mathrm{pH}$ meter. Three measurements were taken for one sample. Before the readings were observed, $\mathrm{pH}$ meter was calibrated using $\mathrm{pH}$ 7.01, 4.01, and 10.01 buffer solutions, respectively.

\section{Viscosity}

The viscosity of nanoemulsion was measured using the Brookfield viscometer at room temperature $\left(25^{\circ} \mathrm{C} \pm 2^{\circ} \mathrm{C}\right)$. Viscosity measurements used two spindles speed and experiments were conducted three times [12].

\section{Nanoemulsion particle size measurement}

Particle size was measured using Vasco ${ }^{\gamma}$ CORDOUAN Technologies Particle Size Analyzer.

\section{Centrifugation test}

The centrifugation test was performed at the beginning and after the preparation was made by measuring one time. The microemulsion preparation was inserted into centrifugation tube then centrifuged at $3750 \mathrm{rpm}$ for $5 \mathrm{~h}[13]$

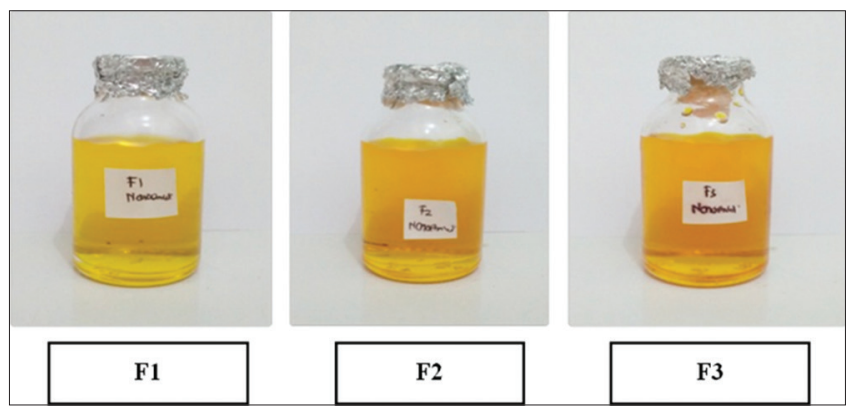

Fig. 1: Red palm olein nanoemulsion after 12 weeks storage

Table 1: Formulas of RPO nanoemulsion

\begin{tabular}{llll}
\hline Ingredients & \multicolumn{2}{l}{ Formula } & \\
\cline { 2 - 4 } & I (\%w/w) & II $(\% \mathbf{w} / \mathbf{w})$ & III $(\% \mathbf{w} / \mathbf{w})$ \\
\hline RPO & 5 & 10 & 15 \\
Tween 80 & 40 & 40 & 40 \\
Sorbitol & 20 & 20 & 20 \\
Methylparaben & 0.1 & 0.1 & 0.1 \\
Propylparaben & 0.02 & 0.02 & 0.02 \\
Aquadest ad & 100 & 100 & 100 \\
\hline
\end{tabular}

RPO: Red palm olein

\section{RESULTS AND DISCUSSION}

\section{Organoleptic test}

Fig. 1 and Table 2 shows that the nanoemulsion stored at room temperature remains clear for up to 12 weeks, the color and smell are unchanged and no any creaming. The formation of creaming in the preparation is due to the formation of aggregates from the inner phase which has a greater tendency to rise to the surface. According to Sinko [14], creaming is the emulsion separation into two layers, wherein the one layer contains drip grains (the dispersed phase) more than the other layers. If the dispersed phase density is smaller than the continuous phase, the sedimentation velocity becomes negative. In this nanoemulsion preparation, there were no any coarse grains from various concentrations of RPO.

\section{pH measurement}

Determination of $\mathrm{pH}$ value from RPO nanoemulsion was using digital $\mathrm{pH}$ meter for 12 weeks. Table 3 showed the results of $\mathrm{pH}$ value from three formulas for 12 weeks at room temperature.

\section{Viscosity test}

Determination of the viscosity of the nanoemulsion was performed using a Brookfield DV-E viscometer with the corresponding spindle number at room temperature for 12 weeks. Data of viscosity test result and graph of nanoemulsion viscosity change can be seen in Fig. 2.

Based on the viscosity test results in Fig. 2, it was concluded that the higher concentration of Tween 80 , the viscosity will increase and the longer the storage time, the viscosity will increase. The viscosity of the nanoemulsion preparation was carried out at room temperature for 12 weeks in which the room temperature was a low temperature. This suggests that the lower the storage temperature will increase the viscosity of the nanoemulsion preparation while storage at room temperature also results in an increase in nanoemulsion viscosity. This is consistent with the theory that the storage period will increase the viscosity of the preparation [13]. However, the increase is not so significant.

Nanoemulsion particle size measurement and centrifugation test The results of particle size analyzing are shown in Table 4.

Determination of particle size is done in the $1^{\text {st }}$ week and week 12 . The particle measurement results show that each formula has varying sizes, this is due to the difficulty of homogenizing two different systems, in addition to several other factors, such as duration or speed of stirring, also cause the formula is not homogeneous. Particle sizes from the 5 to 12 weeks increased, because of tween 80 experienced

Table 2: Organoleptic result of RPO nanoemulsion

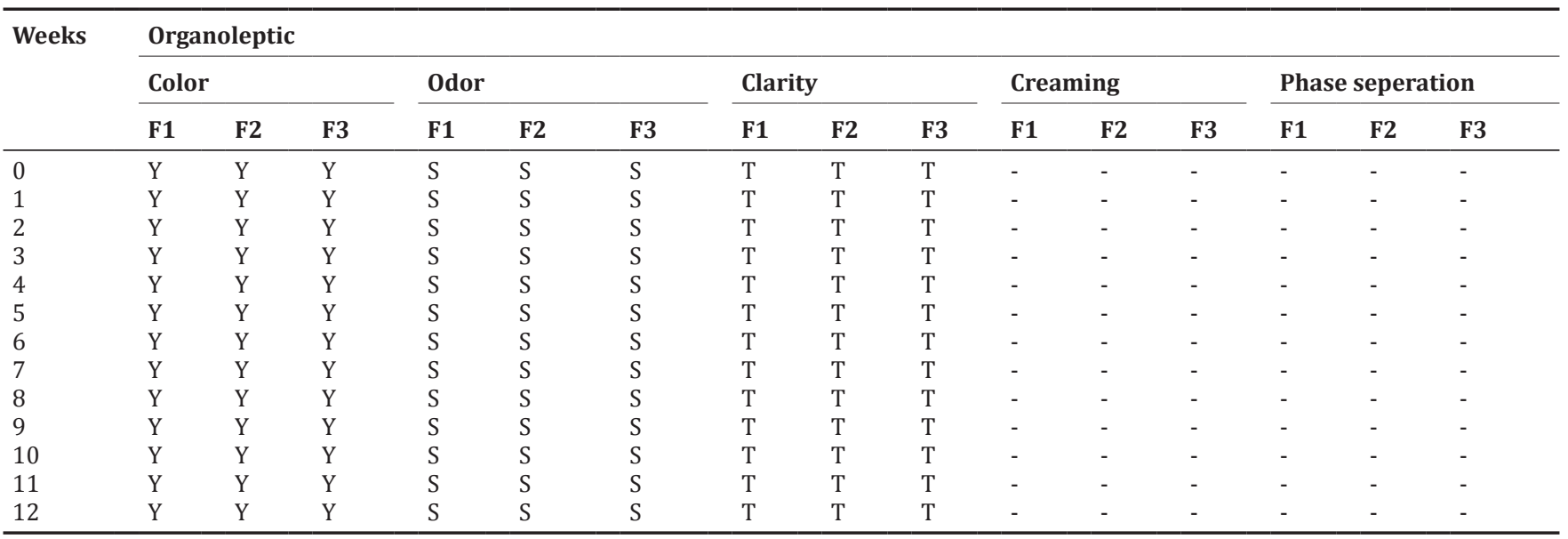

*Y: Yellow, S: Specific, T: Translucent. RPO: Red palm olein 
Table 3: pH value of RPO nanoemulsion

\begin{tabular}{|c|c|c|c|c|c|c|c|c|c|c|c|c|c|}
\hline \multirow[t]{2}{*}{ Formula } & \multicolumn{13}{|c|}{ Time (week) } \\
\hline & 0 & 1 & 2 & 3 & 4 & 5 & 6 & 7 & 8 & 9 & 10 & 11 & 12 \\
\hline F1 & 7.0 & 7.0 & 6.8 & 6.7 & 6.7 & 6.7 & 6.6 & 6.6 & 6.5 & 6.5 & 6.3 & 6.2 & 6.0 \\
\hline F2 & 6.8 & 6.8 & 6.8 & 6.7 & 6.7 & 6.6 & 6.6 & 6.5 & 6.5 & 6.4 & 6.3 & 6.3 & 6.2 \\
\hline F3 & 6.8 & 6.8 & 6.8 & 6.8 & 6.7 & 6.7 & 6.6 & 6.5 & 6.5 & 6.5 & 6.4 & 6.3 & 6.3 \\
\hline
\end{tabular}

RPO: Red palm olein

Table 4: Data of particle size analyzing

\begin{tabular}{lcl}
\hline \multicolumn{2}{l}{ Distribution of particle size $(\mathbf{n m})$} \\
\hline Formula & 0 week & $\mathbf{1 2}$ week \\
\hline F1 & 67.64 & 136.11 \\
F2 & 94.17 & 150.35 \\
F3 & 113.38 & 187.09 \\
\hline
\end{tabular}

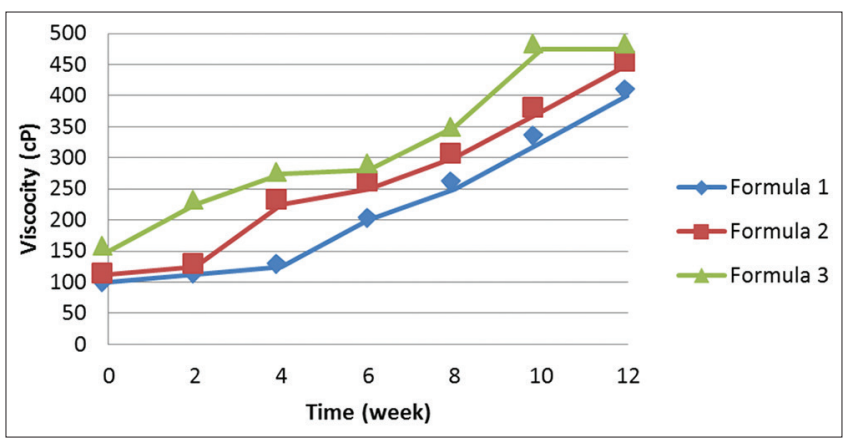

Fig. 2: Viscosity result of red palm olein nanoemulsion

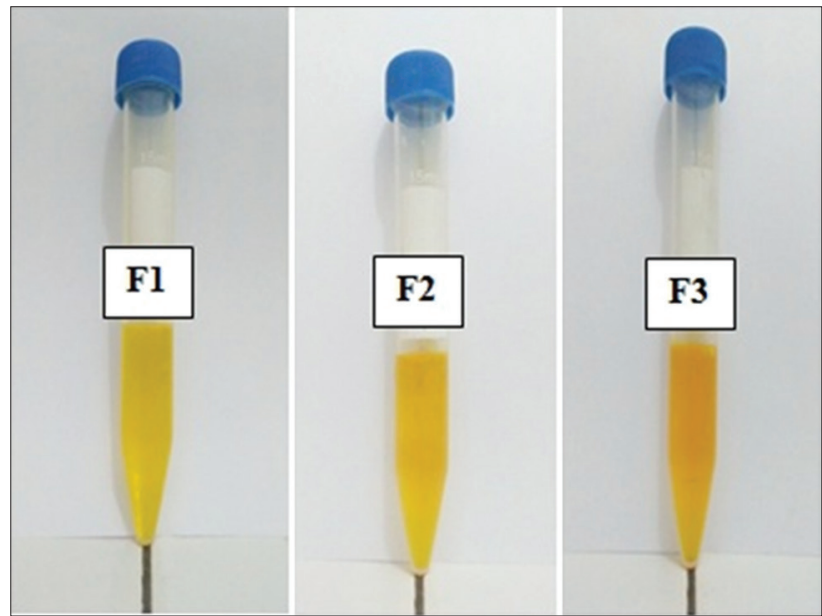

Fig. 3: Centrifugation result of red palm olein nanoemulsion

hydrolysis thus reducing the effectiveness of the nanoemulsion globule interface film layer [15]. Temperature modification during storage can cause a decrease in the effectiveness of surfactants so that oil droplets tend to close together and eventually produce larger droplets. Globule size distribution is an important characteristic of the nanoemulsion system, as it may affect drug release and stability of the preparation $[16,17]$.

The data of the nanoemulsion centrifugation test results can be seen in Fig. 3. All formulas are stable, and there is no phase separation, which means that all formulas are stable against the gravitational force experienced for 1 year. The centrifugation test describes the stability of the dosage because of the effect of Earth's gravity equivalent to
1 year [13]. After testing on all three formulas, F1-F3 showed no any separation. This shows that these three formulas are stable for 1 year because of the influence of gravity.

\section{CONCLUSIONS}

RPO is suitable for preparation of nanoemulsion, and it gives an $\mathrm{o} / \mathrm{w}$ emulsion. Best formula consisting with RPO $5 \%$. As this is the preformulation study stage and further studies will include the need for incorporation of the drug to the best formulations and in vitro, in vivo evaluation of topical delivery.

\section{ACKNOWLEDGMENTS}

The authors would like to thanks Mr. Iksen, S.Farm., M.Si. Department of Pharmacy, STIKes Senior Medan, for his never-ending guidance and suggestions throughout the preparation of this article and Mr. Ahmad Gazali Sofwan, S.Farm M.Si., Apt. Indonesian Oil Palm Research Institute, Indonesia, for the support of this research.

\section{CONFLICTS OF INTEREST}

Declared none.

\section{AUTHORS' CONTRIBUTION}

All the authors have contributed equally.

\section{REFERENCES}

1. Sinaga AG, Siahaan D. The influence of minor component content of palm oil (Elaeis guineensis Jacq.) against antioxidant activity on carotenoid purification process. Pharm Sci Res 2015;2:135-42.

2. Oquntibeju OO, Esterhuyse AJ, Truter EJ. Red palm oil: Nutritional, physiological and therapeutic roles in improving human wellbeing and quality of life. BR J Biomed Sci 2009;66:216-22.

3. Shakeel F, Baboota S, Ahuja A, Ali J, Aqil M, Shafiq S. Stability evaluation of celecoxib nanoemulsion containing tween 80 . Thai $\mathrm{J}$ Pharm Sci 2008;32:4-9.

4. Shah P, Bhalodia D, Shelat P. Nanoemulsion: A pharmaceutical review. Syst Rev Pharm 2010;1:25-6.

5. Devarjan V, Ravichandran V. Nanoemulsion: As modified drug delivery tool. Int J Compr Pharm 2011;2:1-6.

6. Pathan IB, Setty CM. Enhancement of transdermal delivery of tamoxifen citrate using nanoemulsion vehicle. Int J PharmTech Res 2011;3:287-97.

7. Makidon PE. Oil-In-Water Nanoemulsions as Mucosal Vaccine Adjuvants: Characterization, Mechanism, Formulation, and Development of a Nanoemulsion-Based Burkholderia Cenocepacia Vaccine. Dissertation, University of Michigan; 2009.

8. Botes A. Trandermal Delivery of Isoniazid and Rifampicin by pheroid ${ }^{\mathrm{tm}}$ Technology. Dissertation, North-West University; 2007.

9. Wais M, Samad A, Khale A, Aqil M, Khan M. Investigation of nanoemulsion system for transdermal delivery of glibenclamide. Int J Pharm Pharm Sci 2012;4:482-7.

10. Suciati T, Aliyandi A, Sartialdi S. Development of transdermal nanoemulsion formulation for stimulationeous delivery of protein vaccine and artin-m adjuvant. Int J Pharm Pharm Sci 2014;6:536-46.

11. Asmarani FC, Wahyuningsih I. The effect of concentration variation of tween 80 and sorbitol on olive oil antioxidant activity in nanoemulsion formulation. Farmasains 2015;2:223-8.

12. Moffat AC, Osselton MD, Widdop B. Clark's Analysis of Drugs and Poisons. London, UK: Pharmaceutical Press; 2004

13. Lachman L, Lieberman HA, Kanig JL. The Theory and Practice 
of Industrial Pharmacy. Baltimore, USA: Lippincott Williams \& Wilkins; 2012

14. Sinko PJ. Martin's Physical Pharmacy and Pharmaceutical Sciences: Physical Chemical and Biopharmaceutical Principles in the Pharmaceutical Sciences. Baltimore, USA: Lippincott Williams \& Wilkins; 2012

15. Kishore RS, Pappenberger A, Dauphin IB, Ross A, Buergi B, Staempfli A, et al. The degradation of polysorbates 20 and 80 and its potential impact on the stability of biotherapeutics. Pharm Res 2011;28:1194-210

16. Mohanraj VJ, Chen Y. Nanoparticles-a review. Trop J Pharm Res 2006;5:561-73.

17. Giongo JL, Vaucher RD, Ourique AF, Steffler MC, Frizzo CP, Hennemman B, et al. Development of nanoemulsion containing Pelargonium graveolens oil: Characterization and stability study. Int J Pharm Pharm Sci 2016;8:271-6. 